\title{
Aggressive Adult Non-Hodgkin Lymphoma
}

National Cancer Institute

\section{Source}

National Cancer Institute. Aggressive Adult Non-Hodgkin Lymphoma. NCI Thesaurus.

Code C8492.

An aggressive non-Hodgkin lymphoma occurring in adults. Representative examples

include Burkitt lymphoma, precursor B-lymphoblastic lymphoma, precursor T-

lymphoblastic lymphoma, and adult T-cell lymphoma/leukemia. 